\title{
Small Cells in Hepatoblastoma Lack "Oval" Cell Phenotype
}

\author{
S. Badve, M.B.B.S., M.D., F.R.C.Path., L. Logdberg, M.D., Ph.D., A. Lal, M.D., M. T. G. de Davila, M.D., \\ M. A. Greco, M.D., S. Mitsudo, M.D., R. Saxena, M.D., FRCPath. \\ Department of Pathology, Indiana University, Indianapolis, Indiana (SB, RS); Department of Pathology, \\ Emory University, Atlanta, Georgia (LL); Department of Pathology, Northwestern University, Chicago, \\ Illinois (AL); Department of Pathology, Tisch Hospital of New York University (MTDdD, MAG), New York; \\ and Department of Pathology, Montefiore Medical Center (SM), Bronx, New York
}

Hepatoblastoma, a childhood tumor of the liver, is composed of epithelial and mesenchymal elements in varying proportions and at various stages of differentiation. The epithelial element recapitulates the stages of hepatocyte development from the primitive blastema through embryonal hepatocytes to fetal hepatocytes. The blastemal or undifferentiated cells have been postulated to represent neoplastic hepatocyte progenitor cells. In this study, we examine the immunophenotype of the various epithelial cells of hepatoblastoma with special emphasis on the small undifferentiated cell component and compare it with that of adult hepatocytes and hepatic stem (oval) cells. Putative stem cells in the liver can express all of the following markers: $\alpha$-feto protein, CK19 (OV-6), chromogranin A, Bcl-2, HepPar-1, and $\alpha 1$ microglobulin. The latter, like $\alpha$-feto protein, is a plasma protein synthesized by hepatocytes. Both $\alpha 1$ microglobulin and HepPar-1 are expressed in fetal liver cells as early as 7 weeks of intrauterine life. They are also expressed in hepatocellular carcinoma and in hepatocytic cell lines derived from normal fetal or adult liver. Formalinfixed, paraffin-embedded archival tissues from 10 predominantly epithelial hepatoblastomas were immunostained with antibodies directed against CD 34, $\alpha 1$ microglobulin, Bcl-2, HepPar 1, and CK19 using the avidin-biotin-peroxidase method. The undifferentiated small cell component did not express any of the markers studied, namely, Bcl-2, HepPar-1, $\alpha_{1}$ microglobulin, CD34, or CK19. Hepatocyte-like cells were $\alpha 1$ microglobulin- and

Copyright (C) 2003 by The United States and Canadian Academy of Pathology, Inc

VOL. 16, NO. 9, P. 930, 2003 Printed in the U.S.A.

Date of acceptance: June 16, 2003.

Address reprint requests to: Sunil Badve, M.B.B.S., M.D., F.R.C.Path. Department of Surgical Pathology, University Hospital, Room UH-3465, 550 University Boulevard, Indianapolis, IN 46202; fax: 317-274-5346; email: sbadve@iupui.edu.

DOI: $10.1097 / 01 . M P .0000086486 .52370 .81$
HepPar-1-positive, with the intensity of staining correlating with the degree of hepatocytic differentiation. Bcl-2 expression was restricted to areas of ductular differentiation. CK19 was detected in foci that showed duct formation. The small cells of hepatoblastoma did not express HepPar-1, Bcl-2, CK19, $\alpha 1$ microglobulin, or CD34, markers that characterize the immunophenotype of hepatic stem cells ("oval" cells). Thus, this observation raises the following questions: (1) is "hepatoblastoma" a misnomer? (2) is the expression of tumor antigens dysregulated in hepatoblastoma? (3) does the liver have two different types of progenitor cells, oval cells and blastemal cells, with differing immunophenotypes? and (4) do the blastemal cells, rather than oval cells, represent the more primitive progenitor cells of the liver?

KEY WORDS: Hepatoblastoma, Liver neoplasms, Oval cells, Progenitor cells, Stem cells.

Mod Pathol 2003;16(9):930-936

Progenitor or stem cells in the liver, often referred to as oval cells, are best identified in rat models of hepatocarcinogenesis and regeneration, where they are known to have the capacity to proliferate and differentiate into both hepatocytes and biliary epithelial cells. These cells comprise a heterogenous group of cells that is morphologically characterized by ovoid nuclei and scant eosinophilic cytoplasm that variably display features of both hepatocytes and bile duct epithelium. Immunohistochemically, the monoclonal antibody OV-6 is useful in identifying these cells (1). OV-6 was generated using nodular hepatocytes of rat liver as the antigen. In the rat, it recognizes a cytokeratin of molecular weight $56 \mathrm{kDa}(2)$ that shares epitopes with cytokeratins (CKs) 14 and 19. In the rat liver, OV-6 reacts with bile duct epithelium of normal and diseased liver, nodular hepatocytes, and oval cells. The OV-6 epitope has not yet been identified in human liver 
tissue but has been shown to have some relationship with CK19 and CK14, as it does in the rat. In frozen sections from human liver, OV-6 identifies cells in the ductal plate, oval cells, as well as bile ducts and ductules in the fetal liver (3) and oval cells found in focal nodular hyperplasia (4). Charlotte et al. (5) have demonstrated that antiapoptotic protein bcl-2 is expressed in bile ductules and small bile ducts in cirrhotic human liver and focal nodular hyperplasia. This protein appears to colocalize with the OV-6 epitope in the oval cells. Other markers that have been used to identify oval cells include chromogranin A (4) and markers common with hematopoietic stem cells, such as CD34 $(3,6,7)$, Thy-1(7), c-kit $(3,8-10)$, and flt-3 receptor (11).

Hepatoblasts and immature hepatocytes are integral components of the childhood liver tumor, hepatoblastoma. This tumor is composed of epithelial and mesenchymal elements, the latter being represented by spindle cells, cartilage, and bone. Osteoid formation is particularly prominent after chemotherapy (12). The epithelial elements consist of a hepatocytic component that recapitulates the various stages of hepatocyte development, from the primitive blastema to embryonal hepatocytes to fetal hepatocytes. In addition, tumor cells also exhibit bile duct differentiation, including the presence of well-formed bile ducts. It has been postulated that the undifferentiated blastemal cells, a relatively infrequent and focal finding in hepatoblastoma, represent the neoplastic counterpart of progenitor cells in the liver and that the variants of hepatoblastoma represent variable differentiation of these progenitor cells. Ruck et al. $(13,14)$ have demonstrated a population of small epithelial cells in hepatoblastoma that expressed CK7, albumin, and oval cell markers OV-1 and OV-6. This study was designed to examine the immunophenotype of the various epithelial cells in hepatoblastoma and to study the pattern of expression of the oval cell markers in this unique biological environment.

\section{MATERIALS AND METHODS}

Ten predominantly epithelial hepatoblastomas were obtained from Montefiore Medical Center (3 cases) and from New York Medical Center (7 cases). The patients were young children who presented with an enlarging mass in the right upper quadrant of the abdomen. Cases were reviewed, and blocks containing predominantly small cell areas were selected for further analysis.

Serial sections from formalin-fixed, paraffinembedded archival tissue from these cases were obtained and used for immunohistochemical staining. Briefly, $4-\mu \mathrm{m}$ sections were cut from paraffin- embedded blocks. After deparaffinization and hydration, the sections were incubated with hydrogen peroxide to block endogenous peroxidase activity. After antigen retrieval (where necessary), the sections were incubated with primary antibody for 2 hours. The product was detected using the avidin-biotin-peroxidase method using 3,3'-diaminobenzidine as the substrate. Immunostaining was performed using the monoclonal antibody HepPar-1 (Hepatocyte, prediluted; DAKO Corp); CD34 (QBEND 10; Immunotech, France), bcl-2 (Clone 124, prediluted; DAKO), and CK19 (clone RCK 108, DAKO), polyclonal rabbit antibody (K322) directed against $\alpha_{1}$ microglobulin $\left(\alpha_{1} \mathrm{~m}\right)$ (15).

For staining with $\alpha_{1} \mathrm{~m}$ and bcl-2, antigen retrieval was achieved by heating sections in $1 \mathrm{M}$ citrate buffer at $\mathrm{pH} 6.0$ in a microwave oven for $10 \mathrm{~min}$ utes. Protease digestion was employed for CK-19 staining.

\section{RESULTS}

The blocks from the hepatoblastoma that were used for the study contained predominantly epithelial elements; the mesenchymal component was poorly represented. The small cell component was seen either in sheets (Fig. 1A) or as islands interspersed with more mature elements (Fig. 1B). The expression pattern of the various antigens in mesenchymal component is therefore not commented on. The staining pattern of the epithelial cells in all 10 cases was similar (Table 1 ).

In all cases, diffuse cytoplasmic staining of the embryonal, fetal, and mature hepatocytes was seen with $\alpha_{1} \mathrm{~m}$ and HepPar-1 (Fig. 1C). There were a greater number of cells expressing $\alpha_{1} \mathrm{~m}$ than HepPar-1 in any given section. The blastemal cells did not express either of these two hepatocytic markers. Normal bile ducts, sinusoidal cells, and leukocytes did not exhibit any reactivity. CK19 was detected in foci that showed suggestion of duct formation, in addition to normal bile ducts in the adjoining liver tissue. The fetal hepatocytes elsewhere in the section were negative. The blastemal component did not stain with this antibody (Fig. 1D). In slides stained for Bcl-2, the blastemal component was negative. However a small percentage of fetal hepatocytes expressed Bcl-2 (Fig. 1E). These were isolated clusters of cells, which bore no special relationship to vessels or any other definable structure. Expression of Bcl-2 in the normal bile ducts and some lymphoid cells served as internal control. Immunostaining with anti-CD34 antibodies showed staining of endothelium lining sinusoids within the tumor. The epithelial cells, whether of blastemal, embryonal, or fetal types did not show 

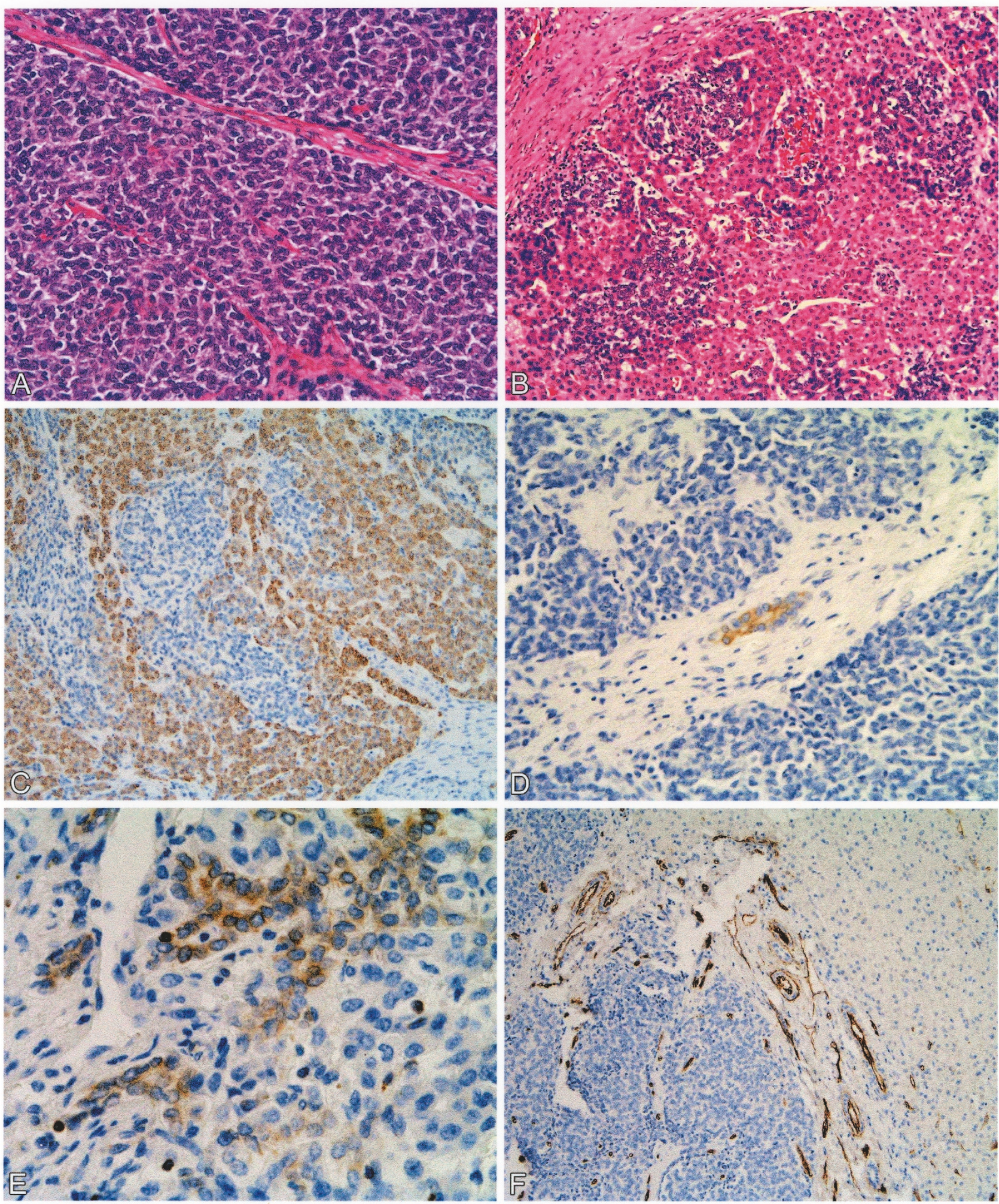

FIGURE 1. The small cell component of hepatoblastoma was seen as small, ovoid cells with a high nucleocytoplasmic ratio arranged either in sheets (A) or as islands interspersed with more mature elements like fetal hepatocytes with a low nucleus-cytoplasm ratio and central uniform nucleus (B). HepPar-1 expression (C) is absent in small cells of hepatoblastoma but is present in the more mature fetal cell type. CK19 (D) and bcl-2 (E) are absent in the small cells of hepatoblastoma but present in the ductal structures. CD34 staining (F) shows no expression in the small cells but is positive in sinusoidal and vascular endothelium. 


\begin{tabular}{|c|c|c|c|c|c|}
\hline & $\begin{array}{c}\text { Hepatoblastoma } \\
\text { Non-Small Cell } \\
\text { Component }\end{array}$ & $\begin{array}{c}\text { Hepatoblastoma } \\
\text { Small Cell } \\
\text { Component }\end{array}$ & $\begin{array}{c}\text { Sinusoidal } \\
\text { Endothelium }\end{array}$ & $\begin{array}{c}\text { Normal Bile } \\
\text { Ducts in } \\
\text { Adjacent Liver }\end{array}$ & $\begin{array}{c}\text { Hepatocytes } \\
\text { in Adjacent } \\
\text { Liver }\end{array}$ \\
\hline Alpha-1 microglobulin & + & - & - & - & + \\
\hline HepPar-1 & + & - & - & - & + \\
\hline CD34 & - & - & + & - & - \\
\hline Bcl-2 & + & - & - & + & - \\
\hline CK19 & + & - & - & + & - \\
\hline
\end{tabular}

All cases showed similar pattern of staining. The small cell component was negative for all markers. Within the non-small cell component of hepatoblastoma staining of the hepatocytic component was seen with HepPar 1 and alpha-1 microglobulin. CK19 with Bcl2 stained the areas that showed biliary differentiation as well as normal bile ducts in the adjacent liver.

any reactivity (Fig. 1F). Within the normal liver, CD34 expression was seen in the portal and periportal vessels.

\section{DISCUSSION}

Progenitor cells with potential for dual differentiation toward hepatocytes and biliary epithelium have been well documented in the rat model of carcinogenesis and regeneration. These cells have an elongated oval shape and contain a dense, oval nucleus surrounded by scant cytoplasm. They are referred to as oval cells because of this distinctive morphology. Although not as numerous or distinctive, similar small, oval, basophilic cells have been seen in the human liver adjacent to hepatic tumors and after massive hepatic necrosis. So-called oval cells are characterized by their positivity for OV-6, Bcl-2, and CD34. Markers of hepatocytic or biliary differentiation are frequently coexpressed along with OV-6, Bcl-2, and CD34, indicating differentiation of oval cells along hepatic or biliary lineage.

Hepatoblastoma is a rare tumor of childhood that recapitulates the developmental stages of the liver, from the undifferentiated hepatoblast (undifferentiated hepatoblastoma) through embryonal hepatocytes (embryonal hepatoblastoma) to fetal hepatocytes (fetal hepatoblastoma). In this scheme, the undifferentiated variant of hepatoblastoma made up of small round to oval cells represents a tumor composed of hepatoblasts, or primitive progenitor cells. If this is true, hepatoblastoma represents the most convincing representation of the oval progenitor cell in humans. Expression of oval cell markers has been shown in hepatoblastoma, supporting this assumption.

In this retrospective study we analyzed the pattern of expression of CK19, Bcl-2, CD34, Hep Par1, and $\alpha 1$ microglobulin in hepatoblastoma, with particular attention to antigen expression in the small, undifferentiated component. The epitope OV-6 is not stable in paraffin sections, and was not used in this retrospective study. The expression of $\alpha 1 \mathrm{mi}-$ croglobulin (15) and HepPar-1 (16), both markers of hepatic differentiation, was restricted to the hepatocyte-like cells. CK-19 was present in areas showing ductular/glandular pattern. None of the markers studied were positive in the small cell component of hepatoblastoma. Lack of reactivity due to antigen loss during formalin fixation can be ruled out by the presence of positive internal controls within the cases studied. Although this is a small study of 10 cases, the absence of detectable antigens in the small cells of hepatoblastoma in all 10 cases was unexpected and raises the following questions: (1) is "hepatoblastoma" a misnomer? (2) is the expression of tumor antigens dysregulated in hepatoblastoma? (3) does the liver have two different types of progenitor cells, oval cells and blastemal cells, each with a different phenotype? and (4) do the blastemal cells represent the more primitive progenitor cells of the liver, as true stem cells should not express any lineage markers of differentiation?

\section{Is Hepatoblastoma a Misnomer?}

Hepatoblastoma is a tumor that is composed of epithelial and stromal elements. The epithelial elements show a range of morphological patterns ranging from small "undifferentiated" cells to mature hepatocytes and bile duct epithelial cells. These morphological observations make it evident that hepatoblastoma has a potential for bidirectional differentiation. This characteristic of hepatoblastoma is also seen in metastases of this tumor.

The existence of cells that have features intermediate between hepatocytes and biliary epithelium has been demonstrated by electron-microscopic studies. Ruck et al. (14) have identified a population of cells that they refer to as "small epithelial cells" in hepatoblastoma. These cell types are characterized by their oval shape, small size (7-18 $\mu \mathrm{m}$ maximum diameter), electron-dense nucleus in which the heterochromatin was seen as small clumps dispersed in nucleoplasm with peripheral condensation; tonofilament bundles; and tight junctions or desmosome-like junctions. The small epithelial cells thus could be differentiated from hepatocytes, bile duct epithelial cells, and cells of Ito (14). However, on occasion, these small epithelial cells showed evidence of lineage differentiation in the 
form of surface microvilli and formation of bile canaliculi with neighboring hepatocytes. The morphological and electron-microscopic evidence would therefore prove that hepatoblastoma is a blastoma; the term is not a misnomer.

\section{Is the Expression of Tumor Antigens}

\section{Dysregulated in Hepatoblastoma?}

Immunohistochemically, oval cells in both the human and rat liver comprise a heterogenous group of cells, with variable expression of a wide array of antigens. Ruck et al. $(13,14)$, observing the coexpression of OV-6 and albumin in the small epithelial cells of hepatoblastoma, have argued that these cells represent the oval cell counterpart in humans. Although it fits with the conventional wisdom, one has to remember that the OV-6 antibody was generated against nodular hepatocytes of rat. It not only reacts with oval cells but also with bile duct epithelial and nodular hepatocytes. The coexpression of OV-6 and albumin therefore does not indicate that the cells are indeed progenitor cells. In a separate study, Roskams et al. (4) have similarly concluded that OV-6 is not purely a marker of progenitor cells. Ruck et al. (14), in another study, examined the expression of CK19 in hepatoblastoma. They noted marked CK19 expression in one case of small cell hepatoblastoma and in embryonal areas of hepatoblastoma. From their descriptions, it appears that at least some of these cells were organized in tubular structures. It is thus possible that these cells are examples of partial bile duct differentiation rather than of oval cells. They also concede that the CK profile of oval cells is similar to that of biliary epithelium. It is therefore important to assess the expression of antigens in undifferentiated cells before asserting the presence of oval cells in hepatoblastoma.

Oval cells have been also shown to express hematopoietic stem cell markers such as CD34, c-kit, and flt-3. It has been postulated that stem cells in normal liver are located periportally within, or in close proximity to, the canals of Hering. Using double immunohistochemical staining, Theise et al. (10) have demonstrated expression of c-kit within cells of the canals of Hering. An alternative concept of the origin of liver stem cells from circulating bone marrow stem cells has been emerging in recent literature. Petersen et al. (17) have reported the derivation of hepatocytes from bone marrow cells in rats on oval cell protocols after bone marrow transplantation. Theise et al. (18) have demonstrated this phenomenon even under physiological conditions, reporting a relatively stable engraftment of $2.2 \%$ over the period of the study. We were therefore interested in the expression of CD34 in hepatoblastoma. Although Ruck et al. (6) have de- scribed CD34 expression in formalin-fixed archival tissue in one of their 12 cases of hepatoblastoma, we did not find CD34 positivity in any of our cases.

Fetal progenitor cells in a number of tissues express Bcl-2, an anti-apoptotic protein. It is expressed in bile ductules and small bile duct epithelium in cirrhotic human liver and focal nodular hyperplasia, but not in hepatocytes. Bcl-2 is also proposed as a marker of pancreatic (islet) stem cells. Demetris et al. (19) have demonstrated the expression of Bcl-2 in "ductular hepatocytes" after submassive hepatic necrosis. Ductular hepatocytes are believed to be a transient amplifying population arising from a progenitor cell located in or near the canals of Hering. Ductular hepatocytes are CD34 and $\alpha$-feto protein negative. Occasional ductular hepatocytes can coexpress HepPar- 1 or $\alpha 1$ antitrypsin and high-molecular weight keratins (AE1), indicative of both ductal and hepatocytic differentiation. Apart from the areas of ductular differentiation, none of the cells in the hepatoblastomas that we studied expressed Bcl-2. HepPar-1 and $\alpha 1$ microglobulin were positive only in cells that morphologically resembled hepatocytes. In general, the numbers of cells expressing $\alpha 1$ microglobulin was greater than that of those expressing HepPar-1.

Analysis of antigen expression is further complicated by the loss and aberrant expression of lineage-specific markers in neoplastic cells. This is exemplified by expression of CK in leiomyosarcomas and by aberrant expression of lymphoid markers in T-cell lymphomas. Extensive studies have similarly shown that keratins in liver tumors lack the fidelity that is associated with normal hepatocytic or biliary differentiation (20-22). Biliary CKs are expressed in malignant hepatocytes, and hepatocytic CKs are expressed in cholangiocarcinomas. Lineage fidelity can sometimes be lost even in benign diseases. Van Eyken et al. (23) have demonstrated that damaged hepatocytes in alcoholic liver disease and in focal nodular hyperplasia (24) can express "bile-duct type" CKs.

It is therefore entirely possible that similar mechanisms may result in loss of "oval cell" markers in progenitor cells in hepatoblastoma. Ruck et al. (13) have demonstrated co-expression of CK7, a marker of biliary differentiation, and albumin, a marker of hepatocytic differentiation in small epithelial cells from cases of hepatoblastoma by immunoelectron microscopy. Whether this represents an altered expression of CK associated with neoplasia or true bidirectional differentiation is unclear. The latter would be a possible explanation if any of the exclusively oval cell markers were lost. However, other cell types within the liver, namely hepatocytes or bile duct epithelium, also express the epitopes recognized by the CK antibodies (OV-6, CK19, or CK7); 
that is, they are not exclusive to the "oval cells." The only non-hepatobilary oval cell marker, CD34, has been reported to be positive in one case of hepatoblastoma (6).

\section{Existence of More than One Population of Stem Cells}

It is now known that more than one cell type contributes to regeneration of the liver. The progenitor cells of the liver traditionally have been thought to reside in the canals of Hering (10), an anatomic structure that represents the hepatobiliary interface. Recent studies have shown the contribution of bone marrow cells to repopulation of the liver $(17,18)$. Interestingly, these bone marrowderived cells localize to the hepatic cords (not canals of Hering) and probably represent a minor facultative pathway.

Yavorkovsky et al. (25) studied the participation of small intraportal stem cells in the restitutive response of the liver after periportal necrosis induced by allyl alcohol. During the restitutive process, they identified null cells in the periportal zone that were positive for $\alpha$-feto protein but negative for OV-6 and glutathione-s-transferase- $p$. They additionally identified intermediate cells positive for $\alpha$-fetoprotein and OV-6; as well as transitional cells that were negative for $\alpha$-fetoprotein but positive for OV-6 and glutathione- $s$-transferase- $p$. Those investigators concluded that there is an intraportal liver stem cell that is able to differentiate into differentiated hepatocytes without a transitional duct oval cell or ductular intermediate. It remains to be seen whether the small cells in hepatoblastoma with a null cell phenotype represent the true "undifferentiated and uncommitted" stem cells of the liver.

In conclusion, hepatoblastoma is a fascinating tumor in its ability to recapitulate the development of the liver. The small undifferentiated cells provide a unique opportunity to study progenitor cells capable of differentiating into various hepatic elements. This study demonstrates that these cells fail to stain with a panel of antibodies, including putative markers for oval cells. We suggest the existence of a nonoval progenitor cell in the liver that represents a more primitive and undifferentiated progenitor cell than the oval cell. Further studies are necessary to characterize the phenotype and nature of this population of cells in the "undifferentiated" hepatoblastoma.

\section{REFERENCES}

1. Bisgaard HC, Parmelee DC, Dunsford HA, Sechi S, Thorgeirsson SS. Keratin 14 protein in cultured nonparenchymal rat hepatic epithelial cells: characterization of keratin 14 and keratin 19 as antigens for the commonly used mouse monoclonal antibody OV-6. Mol Carcinog 1993;7:60-6.

2. Dunsford HA, Sell S. Production of monoclonal antibodies to preneoplastic liver cell populations induced by chemical carcinogens in rats and to transplantable Morris hepatomas. Cancer Res 1989;49:4887-93.

3. Blakolmer K, Jaskiewicz K, Dunsford HA, Robson SC. Hematopoietic stem cell markers are expressed by ductal plate and bile duct cells in developing human liver. Hepatology 1995; 21:1510-6.

4. Roskams T, De Vos R, Desmet V. "Undifferentiated progenitor cells" in focal nodular hyperplasia of the liver. Histopathology 1996;28:291-9.

5. Charlotte F, L'Hermine A, Martin N, Geleyn Y, Nollet M, Gaulard P, et al. Immunohistochemical detection of bcl-2 protein in normal and pathological human liver. Am J Pathol 1994;144:460-5.

6. Ruck P, Xiao JC, Kaiserling E. Immunoreactivity of sinusoids in hepatoblastoma: an immunohistochemical study using lectin UEA-1 and antibodies against endothelium-associated antigens, including CD34. Histopathology 1995;26:451-5.

7. Petersen BE, Goff JP, Greenberger JS, Michalopoulos GK. Hepatic oval cells express the hematopoietic stem cell marker Thy-1 in the rat. Hepatology 1998;27:433-45.

8. Baumann U, Crosby HA, Ramani P, Kelly DA, Strain AJ. Expression of the stem cell factor receptor c-kit in normal and diseased pediatric liver: identification of a human hepatic progenitor cell? Hepatology 1999;30:112-7.

9. Fujio K, Hu Z, Evarts RP, Marsden ER, Niu CH, Thorgeirsson SS. Coexpression of stem cell factor and c-kit in embryonic and adult liver. Exp Cell Res 1996;224:243-50.

10. Theise ND, Saxena R, Portmann BC, Thung SN, Yee H, Chiriboga L, et al. The canals of Hering and hepatic stem cells in humans. Hepatology 1999;30:1425-33.

11. Matsusaka S, Tsujimura T, Toyosaka A, Nakasho K, Sugihara A, Okamoto E, et al. Role of c-kit receptor tyrosine kinase in development of oval cells in the rat 2-acetylaminofluorene/ partial hepatectomy model. Hepatology 1999;29:670-6.

12. Saxena R, Leake JL, Shafford EA, Davenport M, Mowat AP, Pritchard J, et al. Chemotherapy effects on hepatoblastoma. A histological study. Am J Surg Pathol 1993;17:1266-71.

13. Ruck P, Xiao JC, Pietsch T, Von Schweinitz D, Kaiserling E. Hepatic stem-like cells in hepatoblastoma: expression of cytokeratin 7, albumin and oval cell associated antigens detected by OV-1 and OV-6. Histopathology 1997;31:324-9.

14. Ruck P, Xiao JC, Kaiserling E. Small epithelial cells and the histogenesis of hepatoblastoma. Electron microscopic, immunoelectron microscopic, and immunohistochemical findings. Am J Pathol 1996;148:321-9.

15. Logdberg LE, Akerstrom B, Badve S. Tissue distribution of the lipocalin alpha-1 microglobulin in the developing human fetus. J Histochem Cytochem 2000;48:1545-52.

16. Minervini MI, Demetris AJ, Lee RG, Carr BI, Madariaga J, Nalesnik MA. Utilization of hepatocyte-specific antibody in the immunocytochemical evaluation of liver tumors. Mod Pathol 1997;10:686-92.

17. Petersen BE, Bowen WC, Patrene KD, Mars WM, Sullivan AK, Murase $\mathrm{N}$, et al. Bone marrow as a potential source of hepatic oval cells. Science 1999;284:1168-70.

18. Theise ND, Badve S, Saxena R, Henegariu O, Sell S, Crawford $\mathrm{JM}$, et al. Derivation of hepatocytes from bone marrow cells in mice after radiation-induced myeloablation. Hepatology 2000;31:235-40.

19. Demetris AJ, Seaberg EC, Wennerberg A, Ionellie J, Michalopoulos G. Ductular reaction after submassive necrosis in humans. Special emphasis on analysis of ductular hepatocytes. Am J Pathol 1996;149:439-48.

20. Maeda T, Kajiyama K, Adachi E, Takenaka K, Sugimachi K, Tsuneyoshi M. The expression of cytokeratins 7, 19, and 20 
in primary and metastatic carcinomas of the liver. Mod Pathol 1996;9:901-9.

21. Van Eyken P, Sciot R, Desmet VJ. Immunocytochemistry of cytokeratins in primary human liver tumors. APMIS Suppl 1991;23:77-85.

22. Van Eyken P, Sciot R, Callea F, Ramaekers F, Schaart G, Desmet VJ. A cytokeratin-immunohistochemical study of hepatoblastoma. Hum Pathol 1990;21:302-8.

23. Van Eyken P, Sciot R, Desmet VJ. A cytokeratin immunohistochemical study of alcoholic liver disease: evidence that hepatocytes can express "bile duct-type" cytokeratins. Histopathology 1988;13:605-17.

24. van Eyken P, Sciot R, Callea F, Desmet VJ. A cytokeratinimmunohistochemical study of focal nodular hyperplasia of the liver: further evidence that ductular metaplasia of hepatocytes contributes to ductular "proliferation" Liver 1989;9:372-7.

25. Yavorkovsky L, Lai E, Ilic Z, Sell S. Participation of small intraportal stem cells in the restitutive response of the liver to periportal necrosis induced by allyl alcohol. Hepatology 1995;21:1702-12. 